
This report was prepared by E. I. du Pont de Nemours and Company (Du Pont) for the United States Depertment of Energy under Contract DE-ACO9-76SP00001 and is an account of work performed under that Contract. Neither the United States, the United States Department of Energy nor Du Pont, nor any of their employees, makes any warranty, express or implied, or asummes any legal liability or responsibility for the accuracy, completeness, or usefulness of any information, apparatus, product, or process disclosed herein, or represents that its use will not infringe privately owned rights. Reference herein to any specific commerical product, process, or sorvice by trade name, mark, manufacturer, or otherwise does not necessarily constiture or imply endorsement, recommendation, or favoring of same by Du Pont or by the United States Government or any agency thereof. The views and opinions of authors expressed herein do not necessarily state or reflect those of the United States Government or any agency thereof.

Printed in the United States of America

Available from

Netional Technical information Service

U. S. Dopartment of Commerce

5285 Port Royal Roed

Springfield, Virginia $2216 t$

Price: Printed Copy A03; Microfiche A01 
DP-1594

Distribution Category: UC-4

\section{DISSOLUTION OF ION EXCHANGE RESIN BY HYDROGEN PEROXIDE}

S. C. LEE

Approved by:

H. D. Harmon

Actinide Technology Division

Publication Date: August 1981

E. I. du Pont de Nemours \& Co. Savannah River Laboratory Aiken, SC 29808

PREPARED FOR THE U. S. DEPARTMENT OF ENERGY UNOER CONTRACT DE-ACO9-76SRO0001 


\section{ABSTRACT}

The resin dissolution process was conducted successfully in full-scale equipment at the SRL Semiworks. A solution containing $0.001 \mathrm{Me}^{2+}$, or $\mathrm{Fe}^{3+}$, and 3 vol $\mathrm{K}_{2} \mathrm{H}_{2}$ in $0.1 \mathrm{M} \mathrm{HNO}_{3}$ is sufficient to dissolve up to 40 vol \% resin slurry (Dowex $50 \mathrm{~h}^{\circ} \mathrm{X} 8$ ). Foaming and pressurization can be eliminated by maintaining the dissolution temperature below $99^{\circ} \mathrm{C}$. The recommended dissolution temperature range is 85 to $90^{\circ} \mathrm{C}$. Premixing hydrogen peroxide with all reactants will not create a safety hazard, but operating with a continual feed of hydrogen peroxide is recommended to control the dissolution rate. An air sparging rate of 1.0 to $1.5 \mathrm{scfm}$ will provide sufficient mixing. Spent resin from chemical separation contains DTPA (diethylenetriaminepentaacetic acid) residue, and the resin must be washed with $0.1 \mathrm{M} \mathrm{NH} \mathrm{NH}_{4} \mathrm{OH}$ to remove excess DTPA before dissolution. Gama irradiation of resin up to $4 \mathrm{kh}-\mathrm{hr} / \mathrm{L}$ did not change the dissolution rate significantly. 
CONTENTS

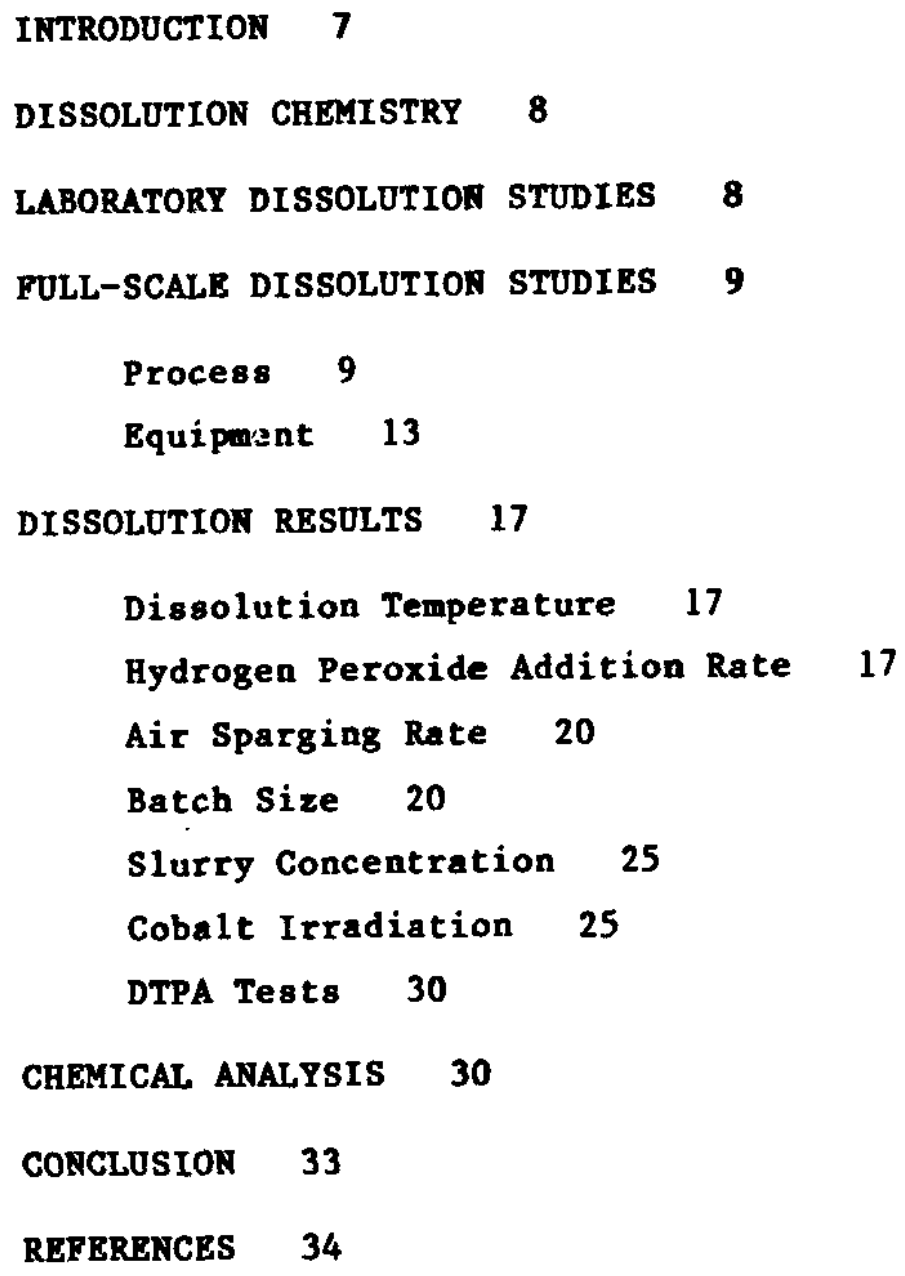




\section{LIST OF ILLOSTRATIONS}

\section{Figures}

1. Laboratory Dissolution Apparatus 10

2. Foam Production During Resin Dissolution 11

3. Resin Dissolution Process 12

4. Resin Sampling System 14

5. Dissolution Vessel 15

6. Resin Storage Tank and Condenser 16

7. Effect of No Temperature Control on Peak Dissolution Pressure 18

8. Effect of Temperature on Dissolution 19

9. Effect of $\mathrm{H}_{2} \mathrm{O}_{2}$ Addition Rate on Dissolution 21

10. Effect of Premixing $\mathrm{H}_{2} \mathrm{O}_{2}$ With Resin on Dissolution 22

11. Effect of Air Sparging Rate on Dissolution 23

12. Effect of Batch Size on Dissolution With Temperature Control 24

13. Effect of Resin Concentration on Dissolution 26

14. Effect of Irradiated Resin on Dissolution 27

15. Resin Bead Before and After ${ }^{60}$ Co Irradiation 28

16. Resin Beads Irradiated by ${ }^{241}$ Am to Two kh-hr/L 29

17. Effect of Resin With DTPA Residue on Dissolution 31

Table

1. Typical Analytical Data for Dissolution Products 32 
DISSOLUTION OF ION EXCHANGE RESIN BY HYDROGEN PEROXIDE

\section{INTRODUCTION}

The Multi-Purpose Processing Facility (MPPF) is designed to separate and recover transplutonium elements by ion exchange and precipitation processes. Because of the high radiation associated with these transplutonium nuclides, the resin from the Rapid Ion Exchange (RIX) columns must be replaced after each run. In the original design, the entire RIX column was to be removed and a new column loaded with fresh resin was to be installed. The old column containing the spent resin was then to be shipped to the Burial Ground for storage as transuranic waste. To reduce the cost of replacing the RIX columns and to eliminate possible environmental hazards associated with the disposal of the spent columns, it was proposed that the MPPF be modified to permit removal of the resin from the columns and to permit reloading of the columns in place with fresh resin.

The spent resin would then need to be dissolved before its transfer to the waste tanks in order to:

- Reduce the potential fire hazards by decreasing local high organic concentrations.

- Reduce the potential corrosion of the carbon steel waste tanks by minimizing local concentrations of organic acids.

- Facilitate the disposal of the resin (1iquids are easier to handle than slurries).

- Enable sampling of the spent resin.

The objectives of this study were to 1) demonstrate that the ful1-scale dissolution of a cation resin can be carried out in a safe and controllable manner and 2) provide data for the preparation of MPPF resin dissolution procedures. 


\section{DISSOLUTION CHEMISTRY}

The ion exchange resin used in the MPPF is a cross-1inked polystyrene sulfonate base cationic resin. This type of resin has been demonstrated ${ }^{1}, 2$ to be soluble in a dilute $\mathrm{H}_{2} \mathrm{O}_{2}-\mathrm{Fe}-\mathrm{HNO}_{3}$ solution. The following evidence indicates that either $\mathrm{Fe}^{2+}$ or $\mathrm{Fe}^{3+}$ must be sorbed by the sulfonate group of the resin for dissolution to proceed:

- Unsulfonated, cross-1inked polystyrene does not dissolve in a $\mathrm{H}_{2} \mathrm{O}_{2}-\mathrm{Fe}-\mathrm{HNO}_{3}$ solution.

- Multiyalent ions interfere with resin dissolution because $\mathrm{Fe}^{2+}$ or $\mathrm{Fe}^{3+}$ has to compete with these ions for ion exchange sites.

- The dissolution is hindered if the ion exchange sites are damaged by radiation.

- The dissolution is hindered if $\mathrm{Fe}^{2+}$ or $\mathrm{Fe}^{3+}$ is converted to an anionic or neutral complex by a complexing agent such as DTPA (diethylenetriaminepentaacetic acid).

It is hypothesized that the dissolution process takes place according to the following mechanism:

$$
\begin{aligned}
& \mathrm{Fe}^{3+}+\mathrm{H}_{2} \mathrm{O}_{2}+\mathrm{Fe}^{2+}+\mathrm{HO}_{2} \cdot+\mathrm{H}^{+} \\
& \mathrm{Fe}^{2+}+\mathrm{H}_{2} \mathrm{O}_{2}+\mathrm{Fe}^{3+}+\mathrm{OH}^{-}+\mathrm{OH} \cdot \\
& \mathrm{OH}^{\bullet}+\text { cross-linked polystyrene sulfonates }+ \text { linear } \\
& \text { polystyrene sulfonates (soluble) }+\mathrm{H}_{2} \mathrm{O}+\mathrm{CO}_{2} \\
& \mathrm{OH}^{\bullet}+\mathrm{H}_{2} \mathrm{O}_{2}+\mathrm{H}_{2} \mathrm{O}+\mathrm{HO}_{2} \cdot \\
& \mathrm{HO}_{2}+\mathrm{Fe}^{3+}+\mathrm{H}^{+}+\mathrm{Fe}^{2+}+\mathrm{O}_{2} \\
& \mathrm{HO}_{2}+\mathrm{Fe}^{2+}+\mathrm{HO}_{2}^{-}+\mathrm{Fe}^{3+}
\end{aligned}
$$

Hydrogen peroxide reacts with iron which was sorbed by the resin, to produce an $\mathrm{OH}$ radical. The $\mathrm{OH}$ radical breaks down the cross linkage of the resin to form linear polystyrene sulfonates that have been shown to be soluble in an aqueous solution. ${ }^{3}$ The overall dissolution process is an exothermic reaction.

\section{LABORATORY DISSOLUTION STUDIES}

Previous studies indicated that foaming associated with resin dissolution was a problem. Foaming will not only contaminate the condensate but also could lead to pressurization of the dissolution vessel as the result of foam pluggage of the vent line. 
Before the full-scale dissolution was started, several bench-scale studies were performed to investigate the dissolution process. Figure 1 gives a sketch of the laboratory resin dissolution equipment. The dissolution mixture contained 33 vol \% resin slurry with $0.1 \mathrm{M}$ nitric acid, $0.001 \mathrm{M}$ iron, and 3 vol \% hydrogen peroxide. Air sparging was used to provide adequate mixing. When the reactants reached $80^{\circ} \mathrm{C}$, dissolution was initiated and proceeded rapidly. The heater was removed as soon as dissolution started. About 15 minutes after dissolution started, the foam height reached a maximum of about two times the liquid height. The dissolution temperature climbed to $104^{\circ} \mathrm{C}$ and stayed there for 10 minutes. When most of the resin was dissolved, the foam height and temperature decreased gradually. Figure 2 gives the relationship between foam height and dissolution time. Foaming was practically eliminated by increasing the air sparging rate to keep the dissolution temperature below $99^{\circ} \mathrm{C}$, the initial boiling point. The dissolution temperature was kept under $99^{\circ} \mathrm{C}$ to minimize foaming in the full-scale dissolution tests.

\section{FULL-SCALE DISSOLUTION STUDIES}

\section{Process}

Ful1-scale dissolution studies were conducted to determine the conditions which would achieve complete dissolution with minimum peak pressurization and essentially no entrainment in the condensate. The effects of dissolution temperature, hydrogen peroxide addition rate, air sparging rate, batch size, resin slurry concentration, resin irradiation, and DTPA residue on dissolution performance were investigated. Based on laboratory dissolution tests, a solution of 3 vol $\% \mathrm{H}_{2} \mathrm{O}_{2}, 0.001 \mathrm{M} \mathrm{Fe}^{3+}$, and $0.1 \mathrm{M} \mathrm{HNO}$ was chosen for this study.

A brief flow diagram of this dissolution process is given in Figure 3. A resin slurry was fed to a dissolution vessel, and the slurry was adjusted to the desired resin/water ratio. Nitric acid and ferric nitrate were added to the slurry to give $0.1 \mathrm{M} \mathrm{HNO}_{3}$ and $0.001 \mathrm{M} F$. Mixing required during dissolution was provided by air sparging at about 1.0 to $1.5 \mathrm{scfm}$. The slurry was then heated, by two $6 \mathrm{kh}$ firerods, to the desired temperature. The temperature was regulated with cooling water and two independent on-off controls for the firerods. The cooling water supply was maintained at a flow rate of $2.5 \mathrm{gpm}$. When the desired temperature was reached, a given quantity of $30 \mathrm{vol} \%$ hydrogen peroxide was gradually metered into the dissolution vessel to control the rate of dissolution. Condensable vapors generated during dissolution were removed by a condenser installed in the off-gas line. Noncondensable gases were fed to the off-gas exhaust system (OGE). The OGE system was maintained at a negative 0.3 in. water column pressure. 


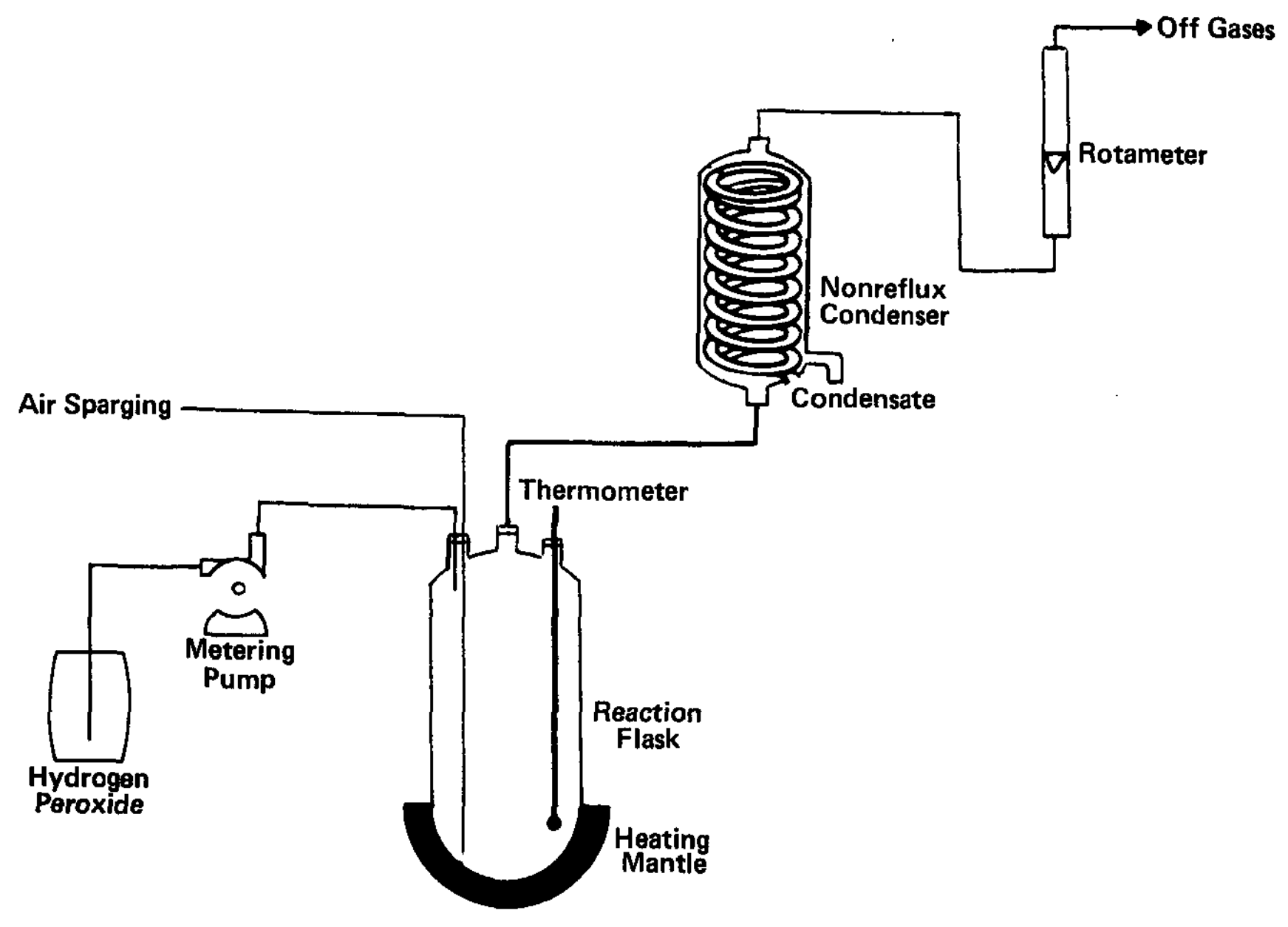

FIGURE 1. Laboratory Dissolution Apparatus 


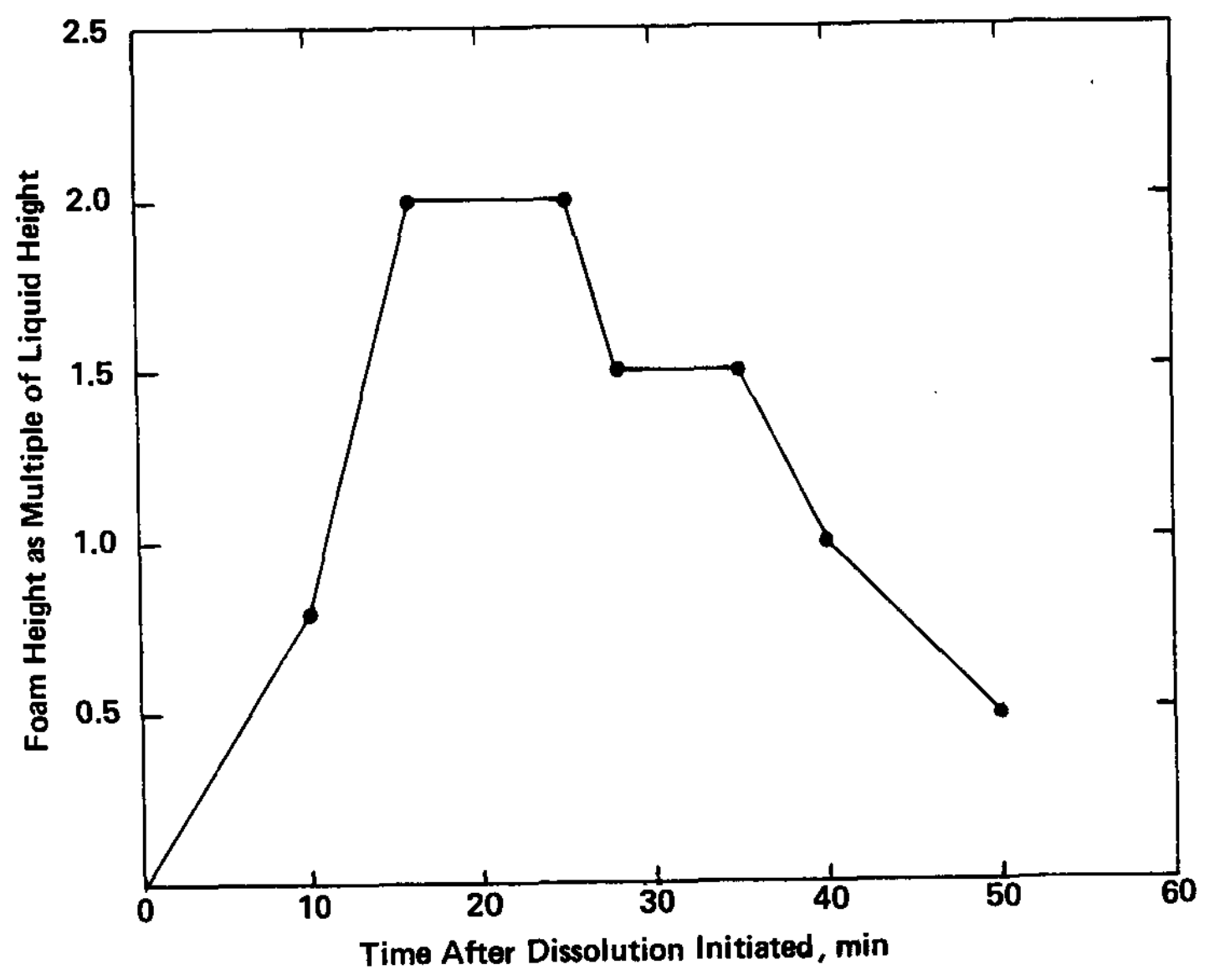

FIGURE 2. Foam Production During Resin Dissolution 


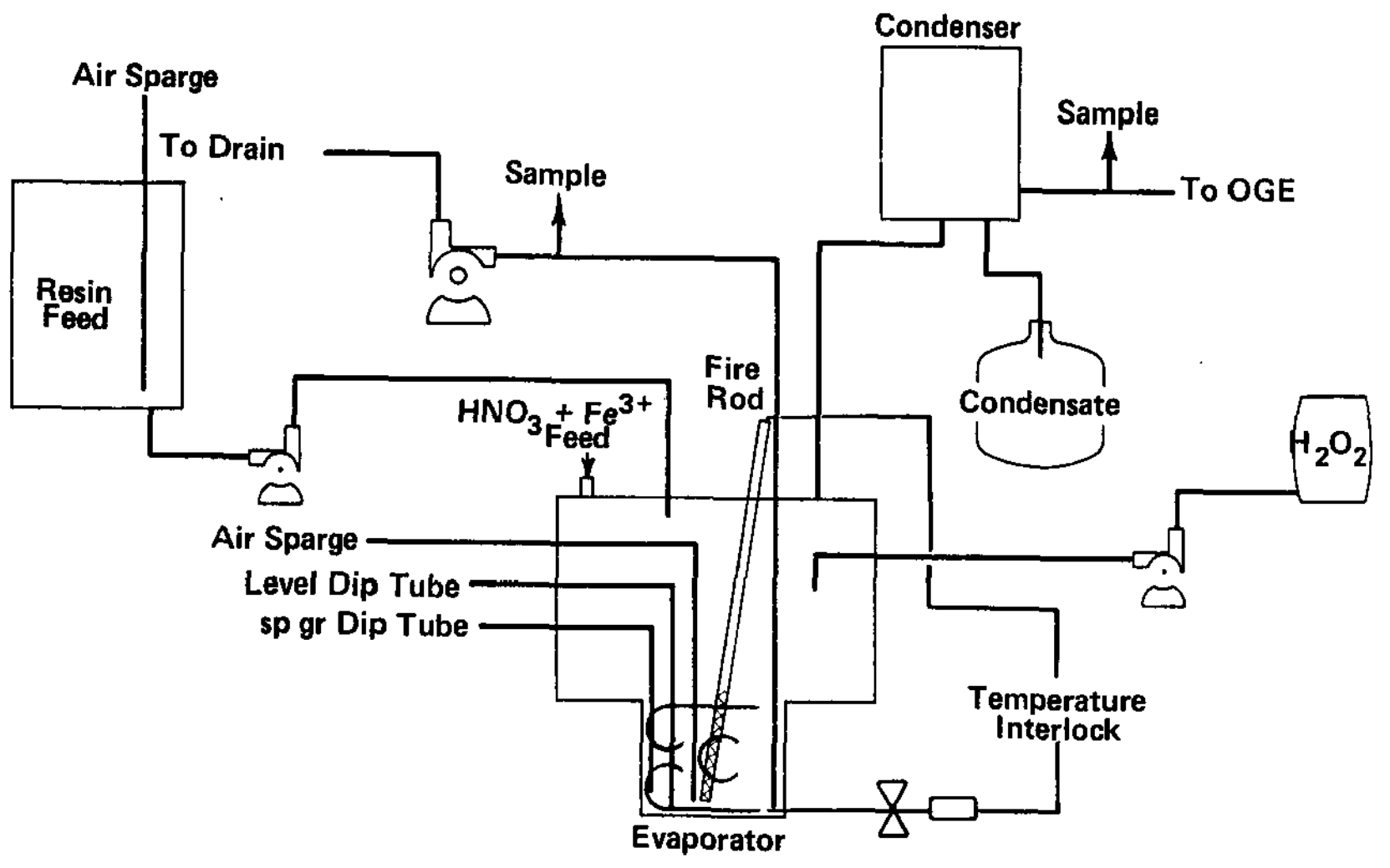

FIGURE 3. Resin Dissolution Process 


\section{Equipment}

\section{Dissolution Vessel}

The volume of the dissolution vessel was $125 \mathrm{~L}$. It was equipped with an air sparger to provide mixing. As a safety precaution, a blow-out leg was installed to provide pressure relief for the dissolution vessel. Any pressurization exceeding 16 in. of water is relieved through this leg. The desired dissolution temperature was maintained by independent on-off controls for both heaters and the cooling water systems. Instruments to measure and record process variables such as level, specific gravity, temperature, and pressure were provided. Dissolution samples were obtained through a sampling jet which was located on the top of the vessel. This jet is a slight modification of the existing MPPF sampling jet by adding a by-pass line (see dotted line of Figure 4). This modification allows the dip leg to be air-purged (open valve $A$ and close valve $C$ ) before any sample is drawn so that the sampling needle will not be plugged by residual resin. Air sparging rates from 1.5 to $5 \mathrm{scfm}$ were found to provide reasonably good mixing for an adequate sampling. An area photograph of the dissolution vessel and its accessories is shown in Figure 5 .

\section{Condenser}

A coil type nonreflux condenser was used $\left(6.7 \mathrm{ft}^{2}\right.$ heat transfer surface). Most of the condensables were removed at the condenser to avoid condensation in the off-gas line. The off-gas temperature from all experiments ranged from 20 to $30^{\circ} \mathrm{C}$.

\section{Hydrogen Peroxide Handling Syatem}

The hydrogen peroxide handling system consisted of a hand pump and two 4-L graduated cylinders enclosed in a stainless steel container (to avoid spilling hydrogen peroxide). During operation, the required amount of hydrogen peroxide was handpumped from a $30-\mathrm{gal}$ drum to a graduated cylinder and then delivered to the dissolution vessel at a given flow rate using a metering pump.

\section{Reain Storage Tank}

A 600-L tank equipped with a mixer was used to store the resin slurry discharged from ion exchange columns. It was established that the mixer set at 150 rpm using a 9 in. impeller was sufficient to keep $500 \mathrm{~L}$ of $12 \%$ resin slurry well mixed. The resin storage tarik and condenser are shown in Figure 6 . 


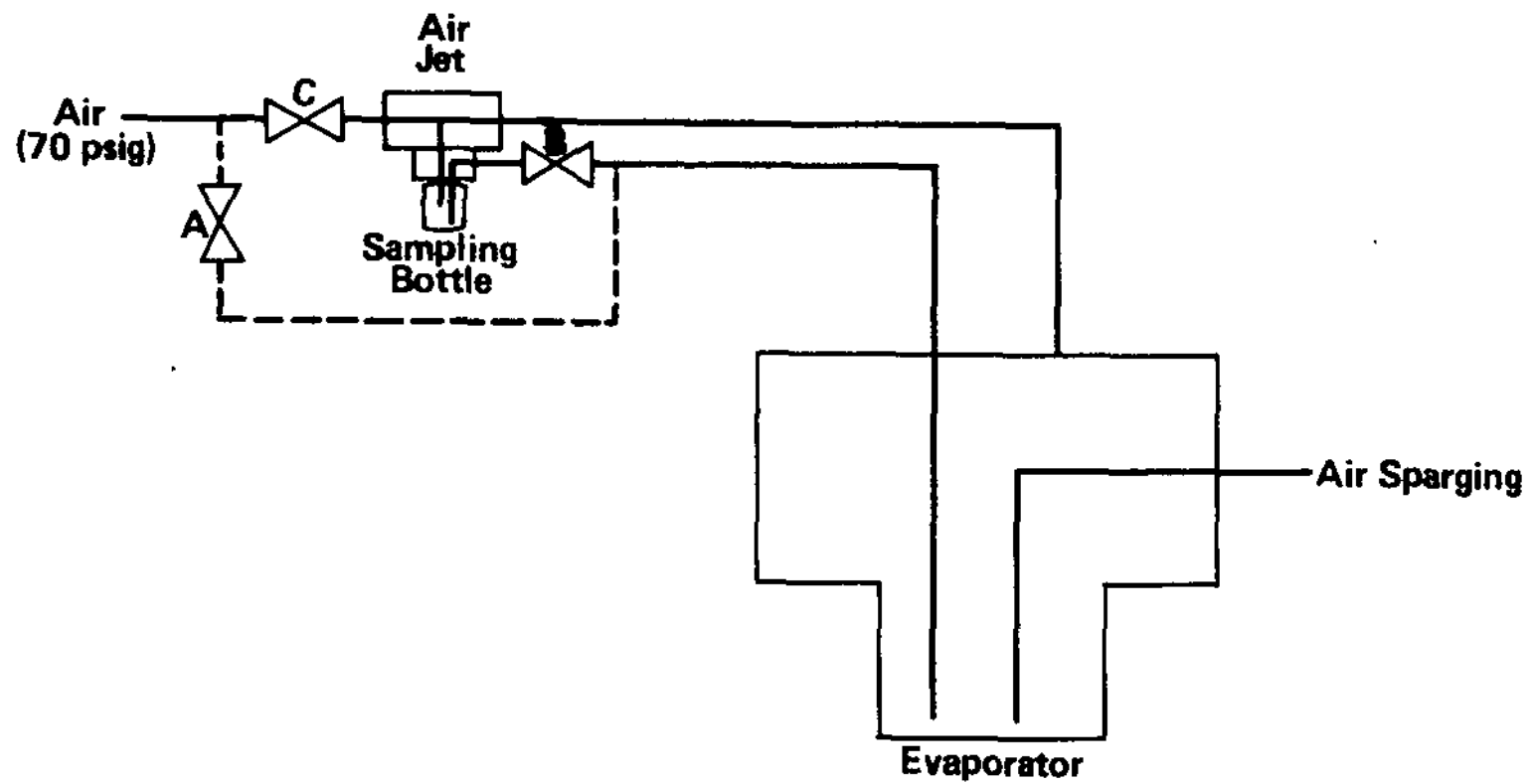

FIGURE 4. Resin Sampling System 


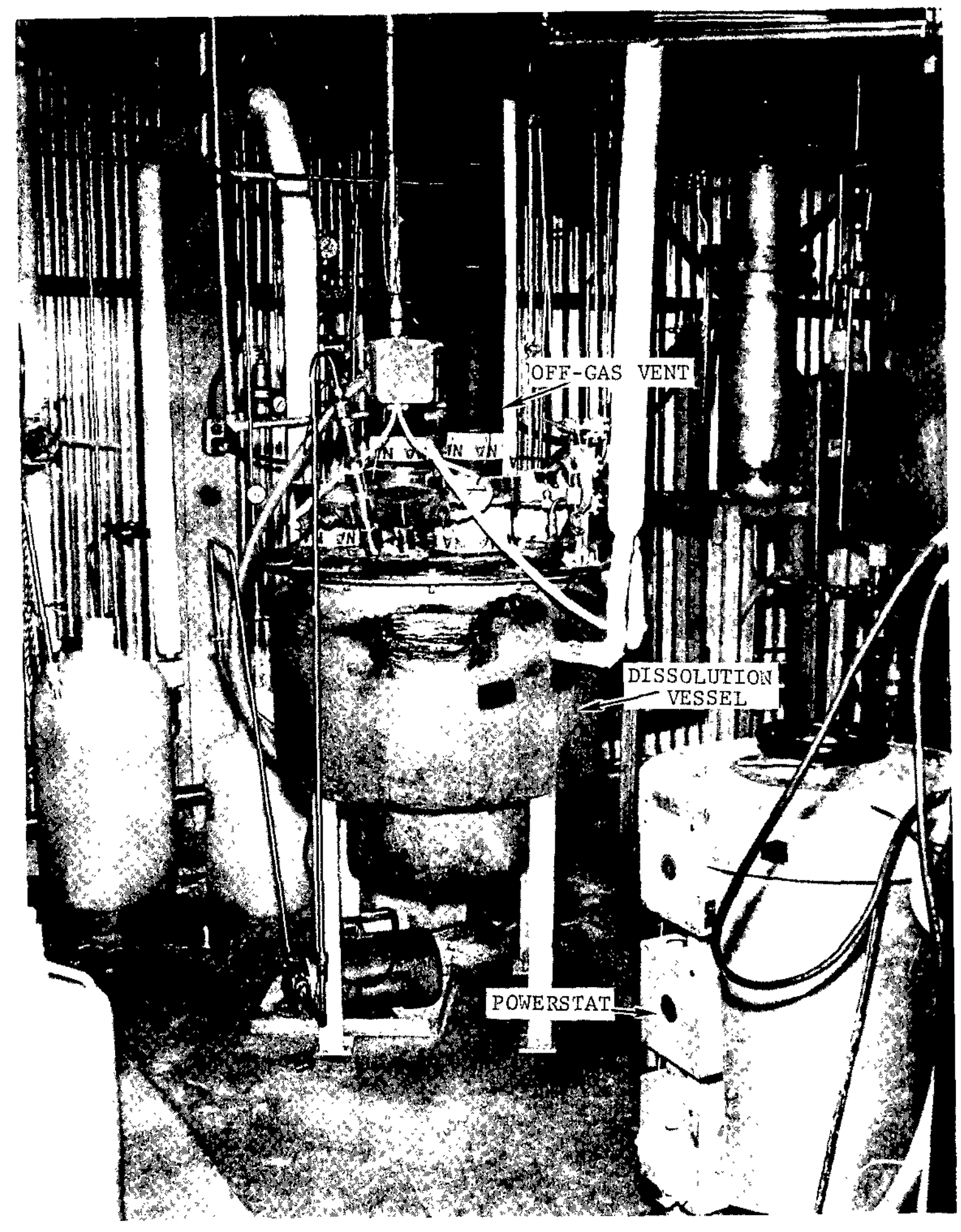

FIGURE 5. Dissolution Vessel 


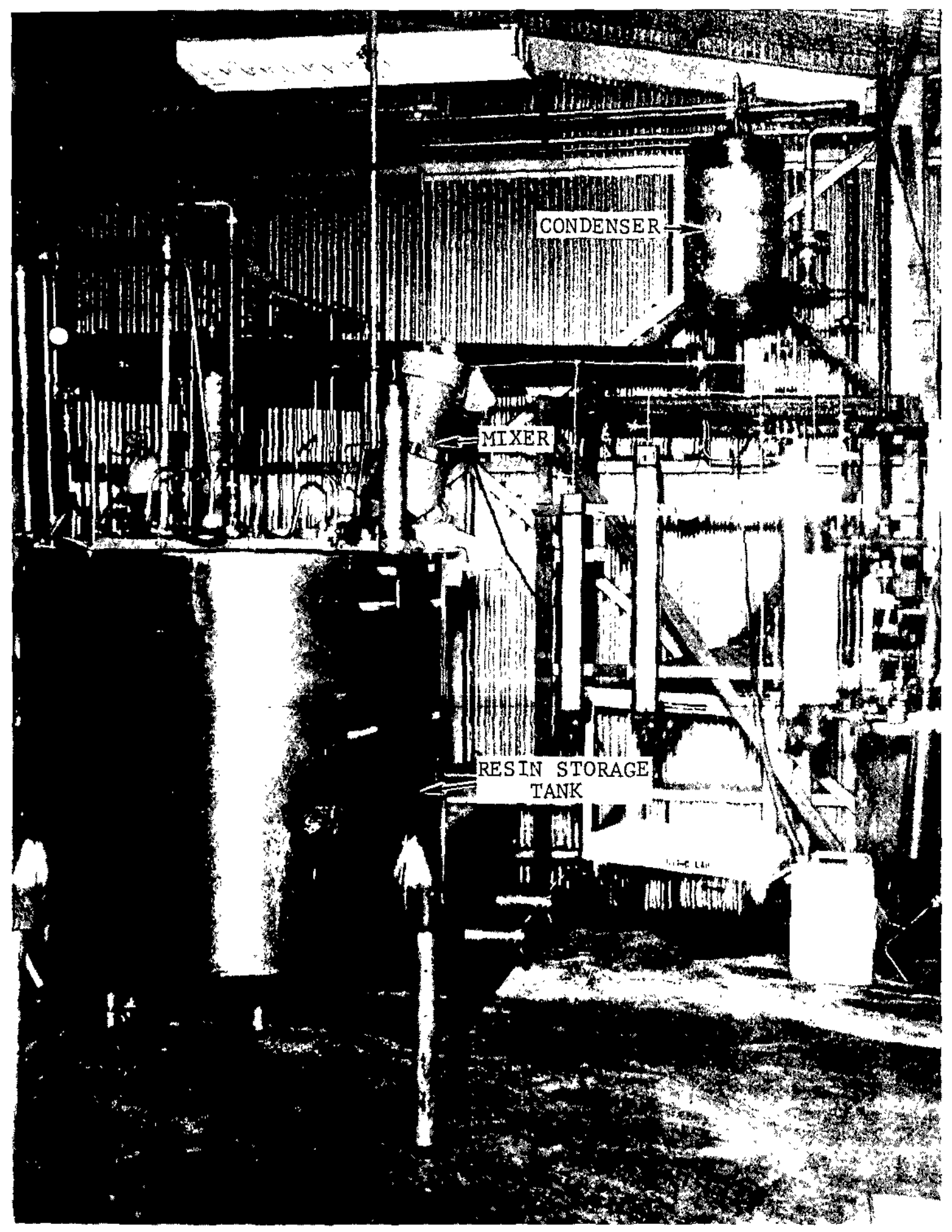

FIGURE 6. Resin Storage Tank and Condenser 


\section{DISSOLUTION RESULTS}

\section{Dissolution Temperature}

Bench-scale tests revealed that controllable dissolution with no excessive foaming could be achieved if the peak dissolution temperature was held below $99^{\circ} \mathrm{C}$. This concept of controlling the temperature of the dissolution vessel was also successfully demonstrated in a full-scale dissolution test. It appears that the excessive pressurization and entrainment are not caused by an increase in dissolution rate when the temperature is raised slightly ( 99 to $100^{\circ} \mathrm{C}$ ). Rather, it is believed that the sudden pressurization and entrainment occur because the dissolved resin solution has an initial boiling point, around $99^{\circ} \mathrm{C}$, as low molecular weight organics are evolved and excessive foam is produced. Figure 7 represents the maximum pressure reached (16 in. of water) when a batch of resin was dissolved without temperature control. Any pressure which exceeded 16 in. of water would be relieved through the blow-out leg of the dissolution vesse1. A number of tests were conducted with controlled dissolution temperatures under $99^{\circ} \mathrm{C}$ (Figure 8). The dissolution time is defined as the time between the start of $\mathrm{H}_{2} \mathrm{O}_{2}$ addition and the final reactivation of the heaters. The reactivation of the heaters is due to the decrease in the heat generated by the exothermic resin dissolution reaction and indicates the completion of the dissolution process. The temperature curve clearly indicates that before dissolution starts, the temperature controller effectively maintained the slurry at the desired temperature. When dissolution was initiated, the reaction heat raised the temperature to the upper limit of the temperature setting. At this point, the solenoid valve was activated to start the flow of cooling water. Then the cooling water kept the dissolution vessel within the desired temperature range. When the dissolution process was nearing completion, the temperature dropped until it reached the lower temperature setting. For the same resin batch size, the dissolution time at 84 to $90^{\circ} \mathrm{C}$ was approximately double the dissolution time at 94 to $99^{\circ} \mathrm{C}$.

\section{Hydrogen Peroxide Addition Rate}

Earlier studies 1,2 on resin dissolution indicated that dissolution involves the elimination, by hydrogen peroxide, of cross-linkages in the resin. Insufficient hydrogen peroxide leads to the incomplete destruction of the cross-linkages and thus, results in only partial dissolution. Results obtained from all bench-scale tests, as well as full-scale tests, have indicated that 3 vol \% hydrogen peroxide (based on final total batch volume) is sufficient for complete dissolution. 


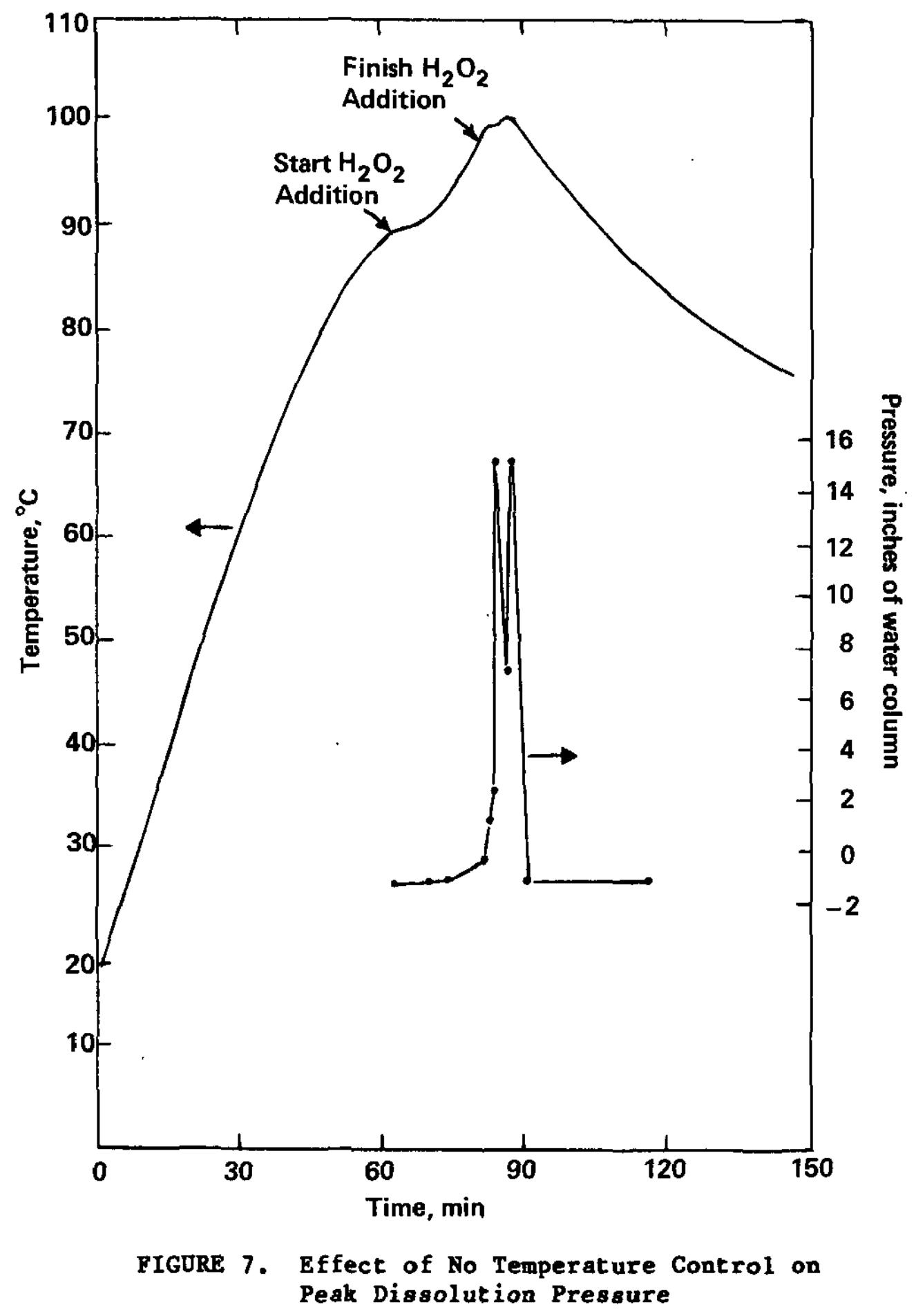




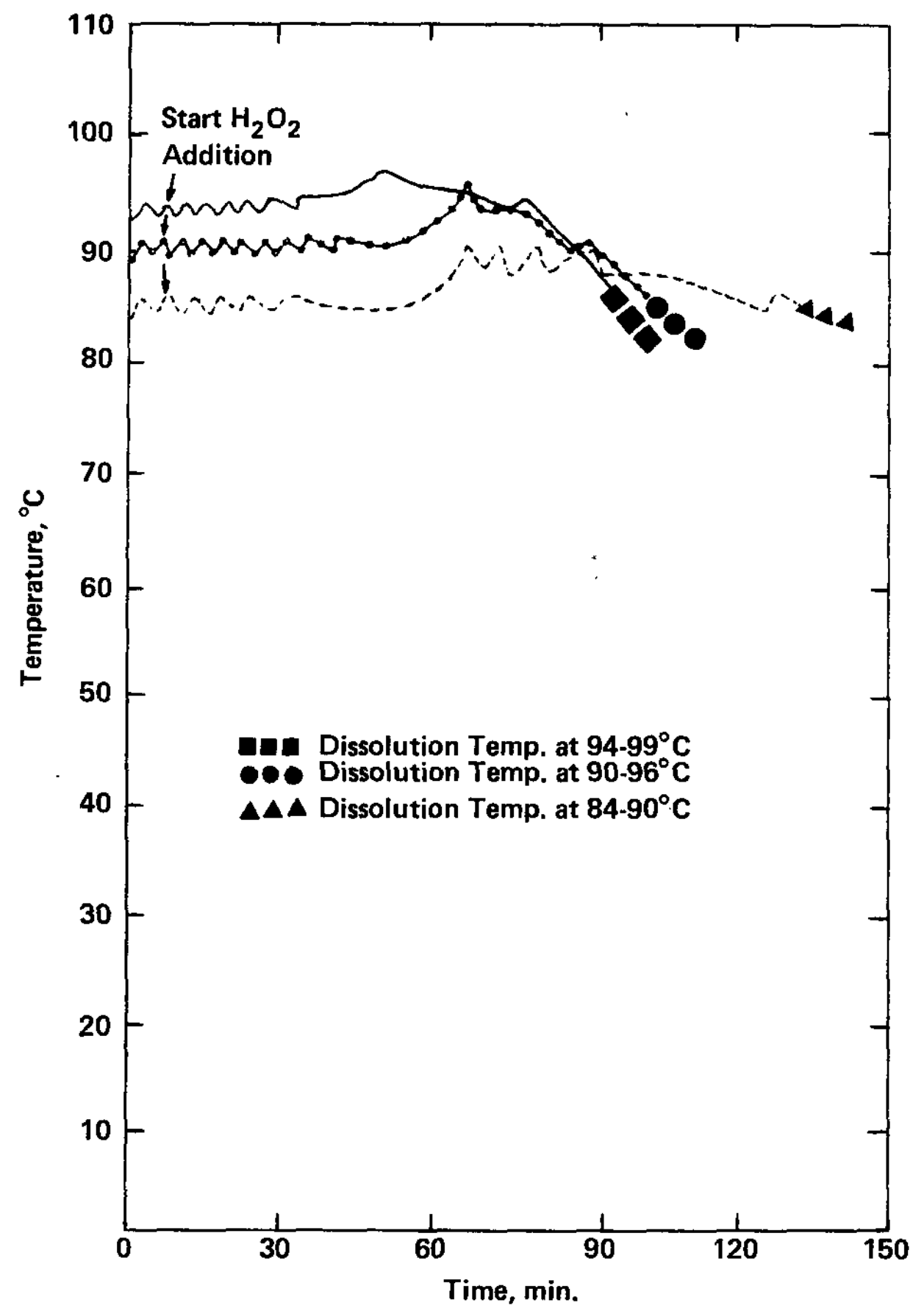

FIGURE 8. Effect of Temperature on Dissolution 
Variations in hydrogen peroxide addition rates were examined; the results are shown in Figure 9. At higher peroxide addition rates, dissolution began earlier. These rates indicate that to begin dissolution, hydrogen peroxide concentration in the slurry has to reach a certain level.

When the required hydrogen peroxide, iron, and acid were added to the resin slurry at room temperature, no dissolution occurred. Once the contents were heated up to $85^{\circ} \mathrm{C}$, dissolution began as indicated by the temperature rise (Figure 10). The cooling water flow is designed to remove the excess reaction heat so that dissolution can be maintained at the desired temperatures ( 85 to $90^{\circ} \mathrm{C}$ ). Although the resin was premixed with hydrogen peroxide, the dissolution was carried out safely under controlled conditions whereby the water cooling capacity $(2.5 \mathrm{gpm})$ to the dissolution vessel was sufficient to remove reaction heat,

\section{Air Sparging Rate}

Air sparging is necessary for mixing resin slurry. Otherwise, the resin tends to settle in the bottom of the dissolution vesse1. Once the immersion heaters are turned on, local hot spots develop. Without agitation, hot spots could damage the heaters.

Air sparging with 1.0 and $1.5 \mathrm{scfm}$ was used in the dissolution tests. Both sparging rates provide adequate mixing, and no significant difference was observed except when dissolution was nearing completion. The higher sparging rate improved the cooling efficiency; i.e., a shorter time was required to cool the contents back to start-up temperature (Figure 11).

\section{Batch Size}

The influence of batch size on dissolution was investigated with and without control of the dissolution temperature. Complete dissolution was achieved for all tests. However, without temperature control, tank pressurization and entrainment (brownish condensate) increased substantially as the batch size was increased from 30 to $42 \%$ of the vessel volume. For batch sizes less than $30 \%$ of the vessel volume, complete dissolution of the resin was achieved with little pressurization or entrainment. For batches containing greater than $36 \%$ of the vessel volume, excessive pressurization (16 in. of water) and entrainment were encountered during dissolution. Ful1-scale dissolution ( $60 \%$ of the vessel volume) with temperature control resulted in controllable dissolution without pressurization and entrainment (Figure 12). 


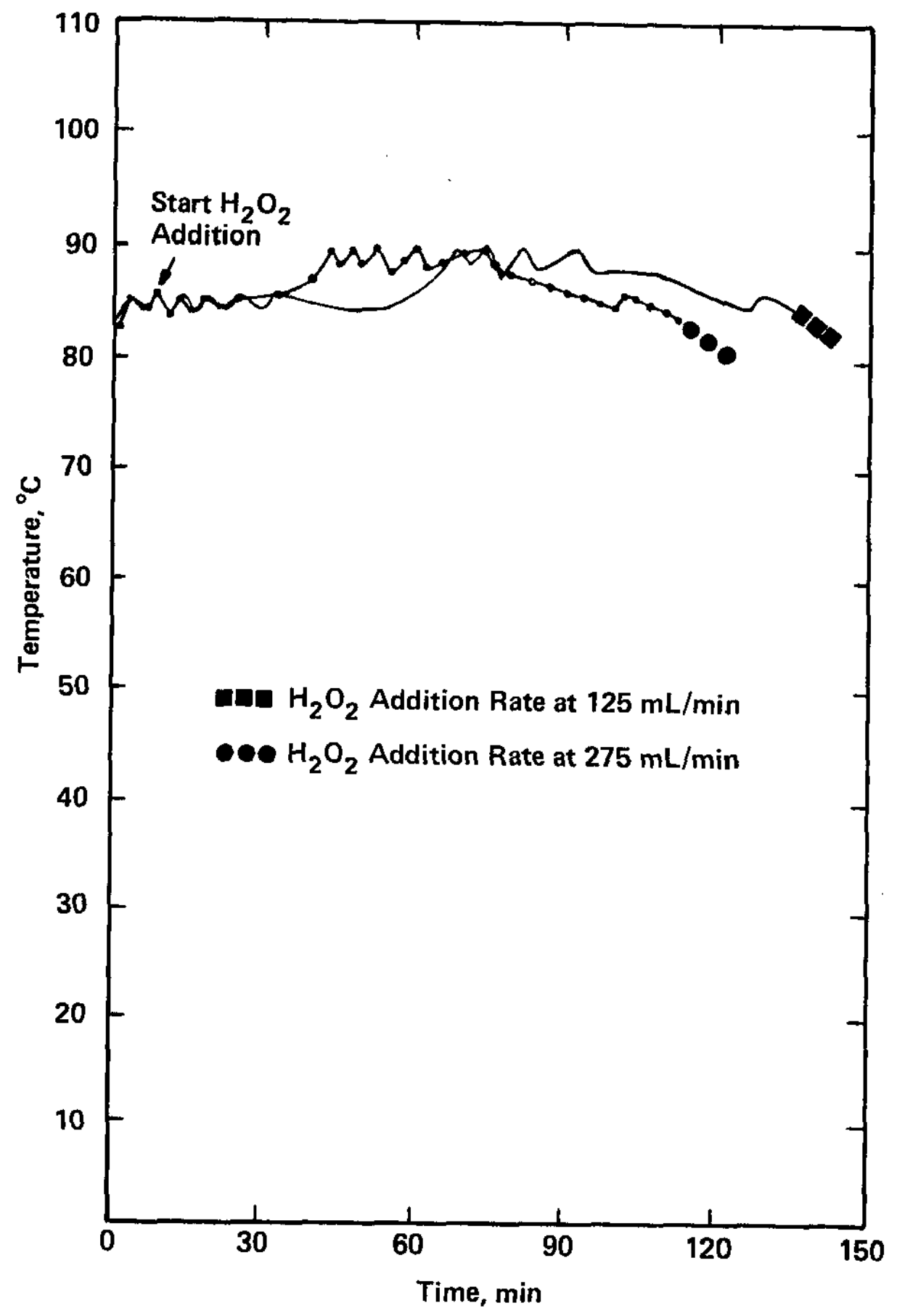

FIGURE 9. Effect of $\mathrm{H}_{2} \mathrm{O}_{2}$ Addition Rate on Dissolution 


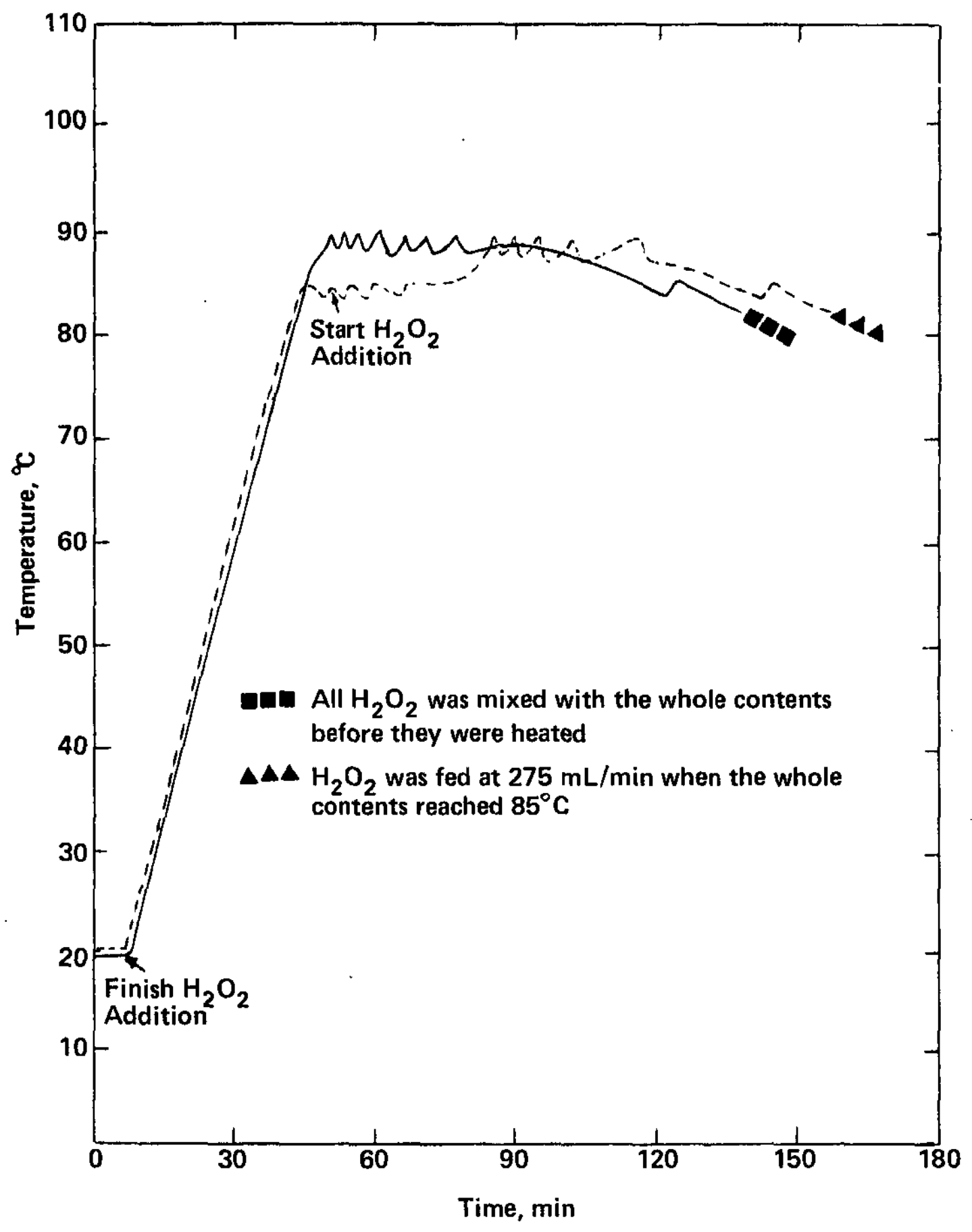

FIGURE 10. Effect of Premixing $\mathrm{H}_{2} \mathrm{O}_{2}$ With Resin on Dissolution 


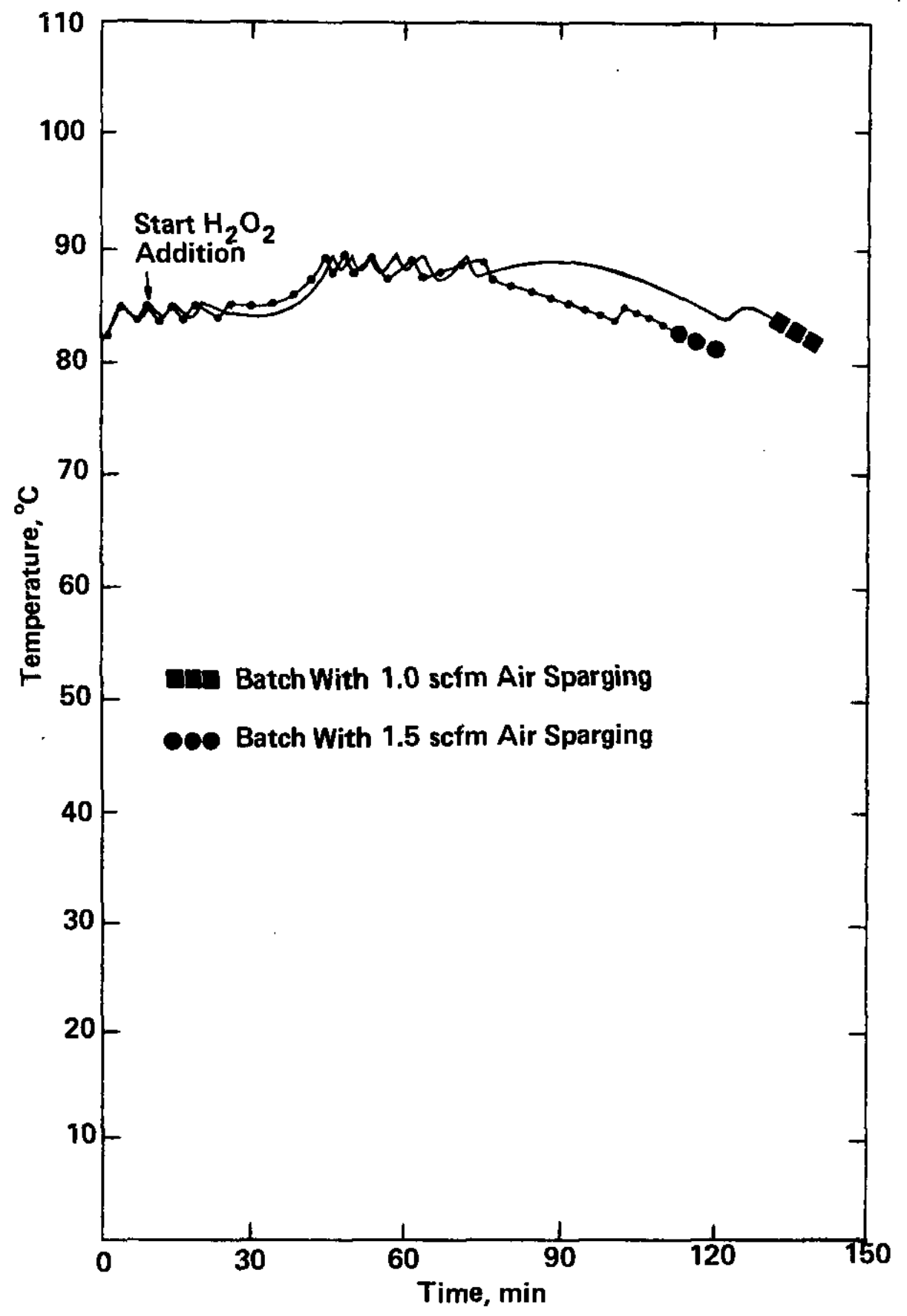

FIGURE 11. Effect of Air Sparging Rate on Dissolution 


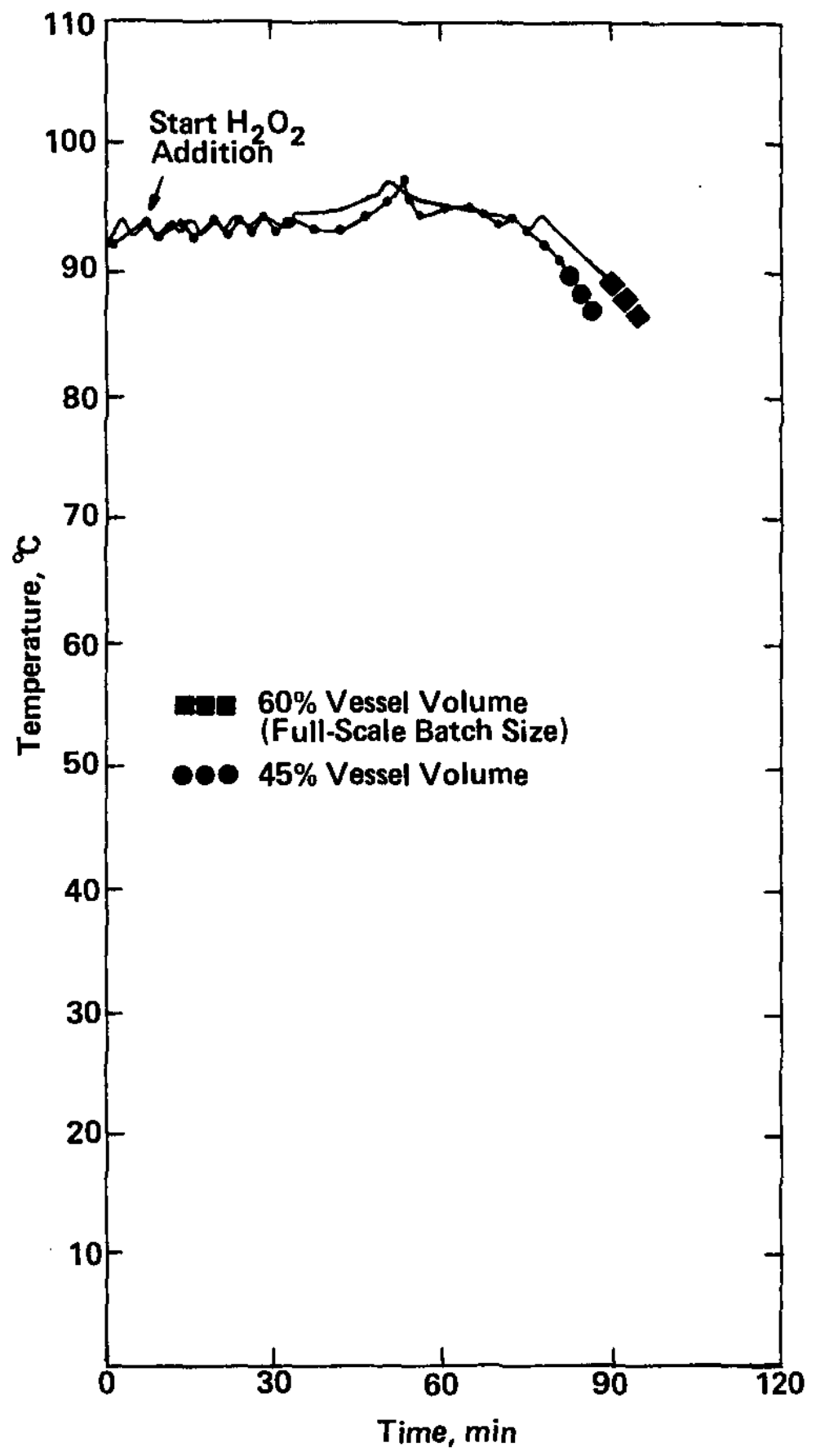

FIGURE 12. Effect of Batch Size on Dissolution With Temperature Control 


\section{Slurry Concentration}

Dissolution tests were conducted to determine the effect of resin slurry concentration ( 9.5 to 40 vol \%) at constant hydrogen peroxide concentration ( 3 vol \%). As the resin slurry concentration is decreased at constant hydrogen peroxide concentration, more severe destruction of the resin would be expected. Analyses of dissolved resin solution indicated that more carbon, as carbon dioxide, was released during dissolution as the resin concentration was decreased; i.e., the carbon/sulfur ratio in the dissolved resin solution was lower. The time required for complete dissolution was decreased slightly as the slurry concentration decreased (Figure 13). No other apparent difference was noticed except a slight discoloration of the condensate in the 9.5 vol \% resin run. The discoloration was shown to be low-boiling organics distilled during dissolution. Based on the total volume of water required to remove resin from four RIX columns (2-, 4-, 6-, and 8-in. dia) at SRL Semiworks, the resin slurry for dissolution in the canyon will contain 12 to 15 vol \% resin. At this range of slurry concentration, dissolution can be carried out successfully.

\section{Cobalt Irradiation}

The ion exchange resin used in the MPPF will be subjected to high-energy radiation. The radiation destroys ion exchange sites and, thus, could interfere with the dissolution process due to reduced iron sorption capacity. To evaluate the effect of irradiation on dissolution behavior, resin was irradiated with ${ }^{60} \mathrm{Co}$ to 4 $\mathrm{kh}^{\prime}-\mathrm{hr} / \mathrm{L}$. Four $\mathrm{kh}-\mathrm{hr} / \mathrm{L}$ is the established radiation dose limit of resin in RIX columns. The ${ }^{60}$ Co irradiated resin dissolved at approximately the same rate as fresh resin (Figure 14).

The radiation effects on ion exchange resin by alpha and gama irradiation were studied at the Rocky Flats Plant. ${ }^{4}, 5$ The physical deterioration of resin by gamma irradiation (up to $4 \mathrm{~kW}$ $\mathrm{hr} / \mathrm{L}$ by ${ }^{60} \mathrm{Co}$ ) was observed as a slight erosion on the surface (Figure 15). The physical damage of the resin by alpha irradiation is more detrimental to the polymer matrix. Irradiation caused the formation of many resin clumps, some of which could not be broken up with a stirring rod. Scanning electron photomicrographs of the irradiated resin illustrate the degradation (Figure 16). Localized fusing appears to form clumps, and there are also examples of bead fragmentation. This physical change by alpha irradiation could impede hydraulic removal of resin from the columns. 


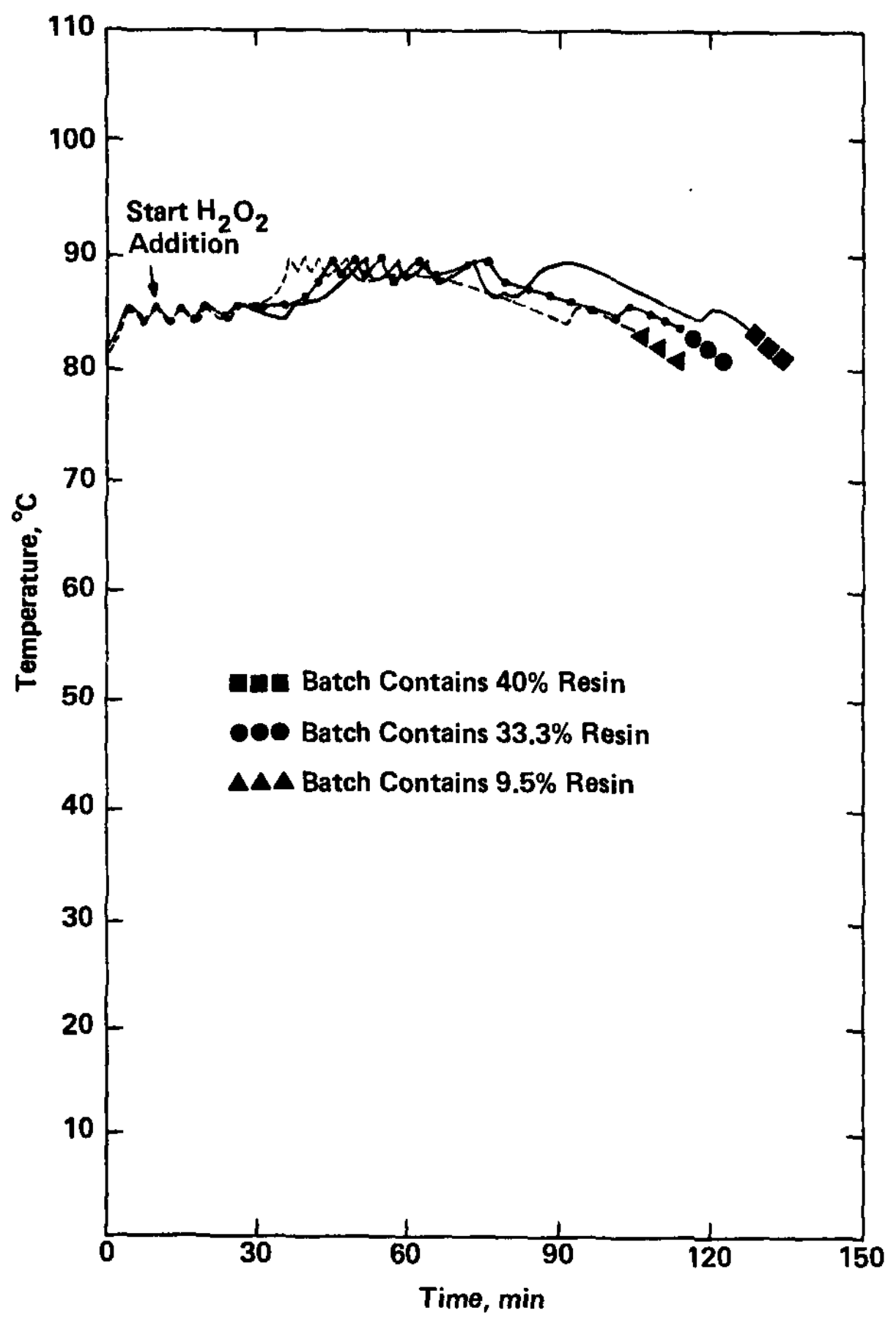

FIGURE 13. Effect of Resin Concentration on Dissolution 


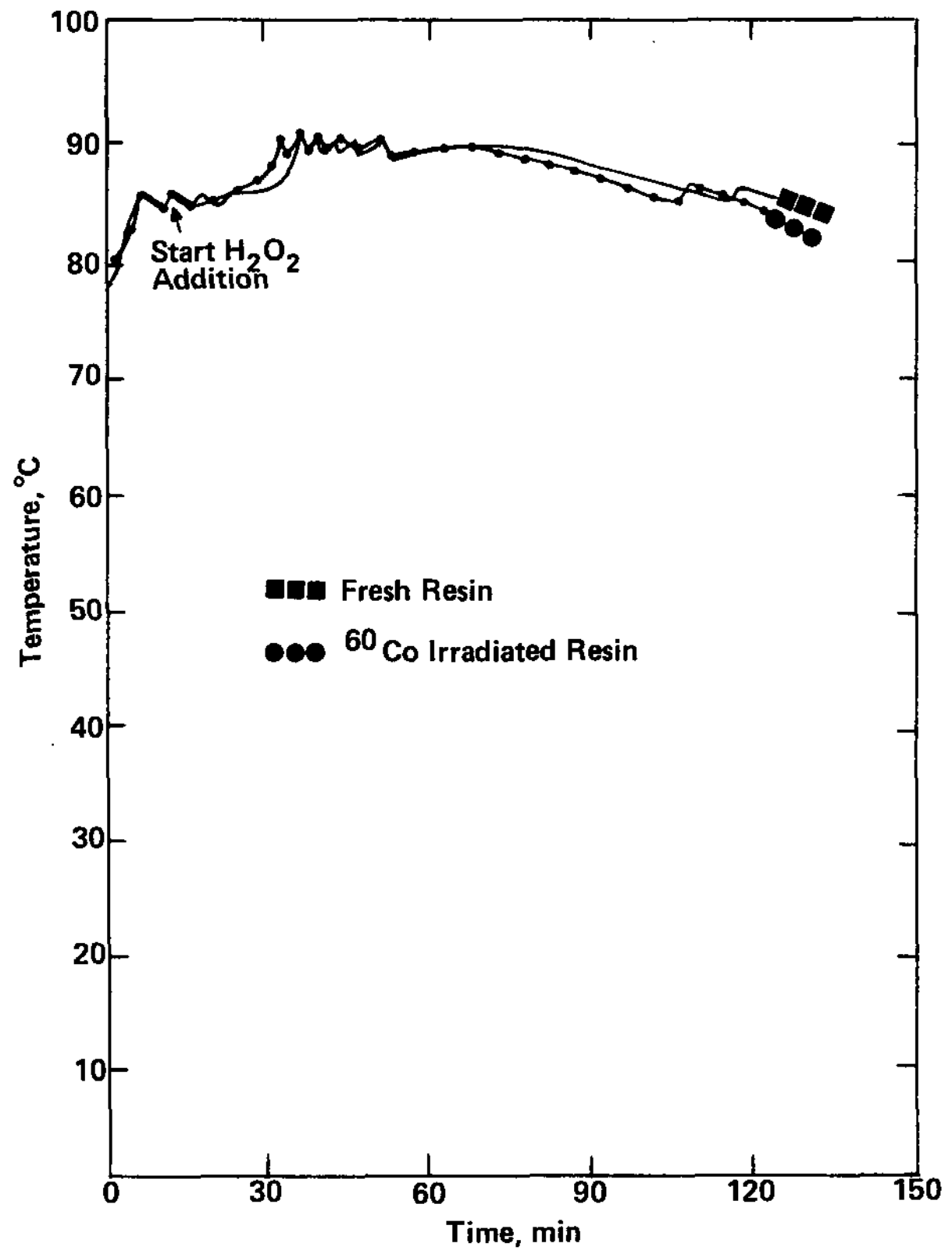

FIGURE 14. Effect of Irradiated Resin on Dissolution 


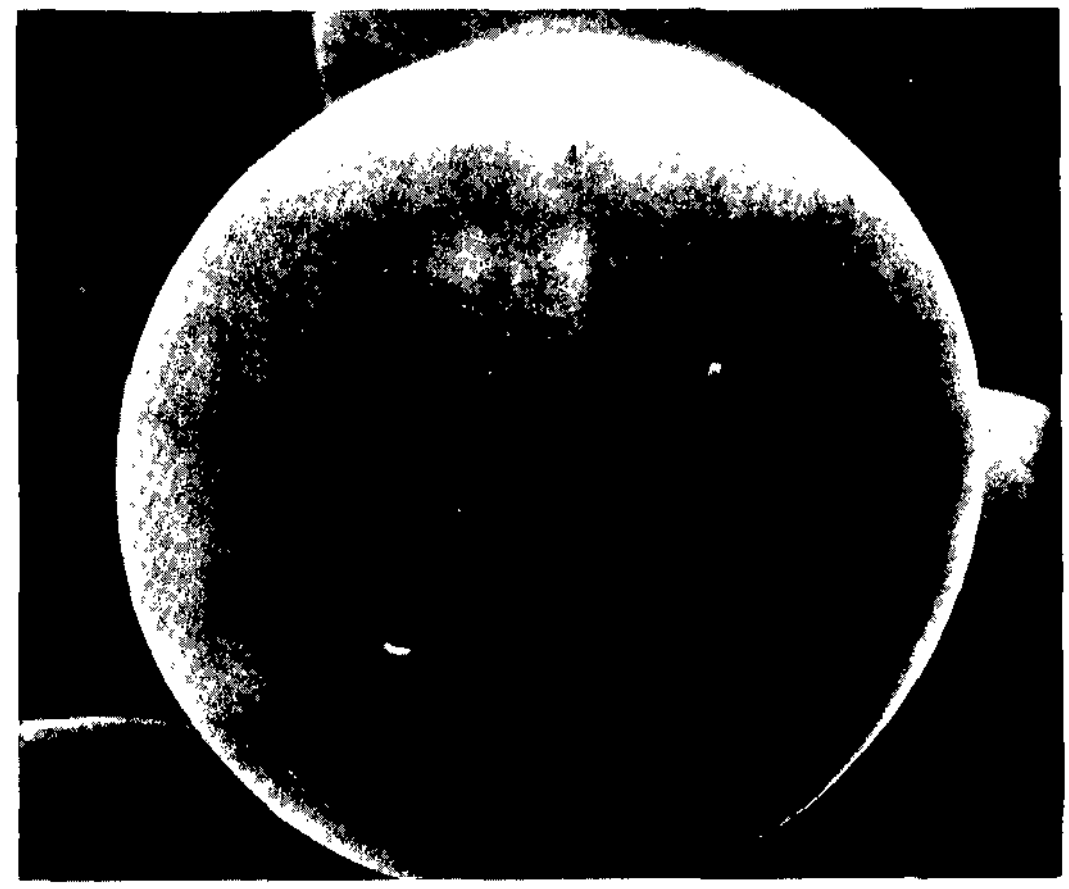

Non-Irradiated Resin (2000X)

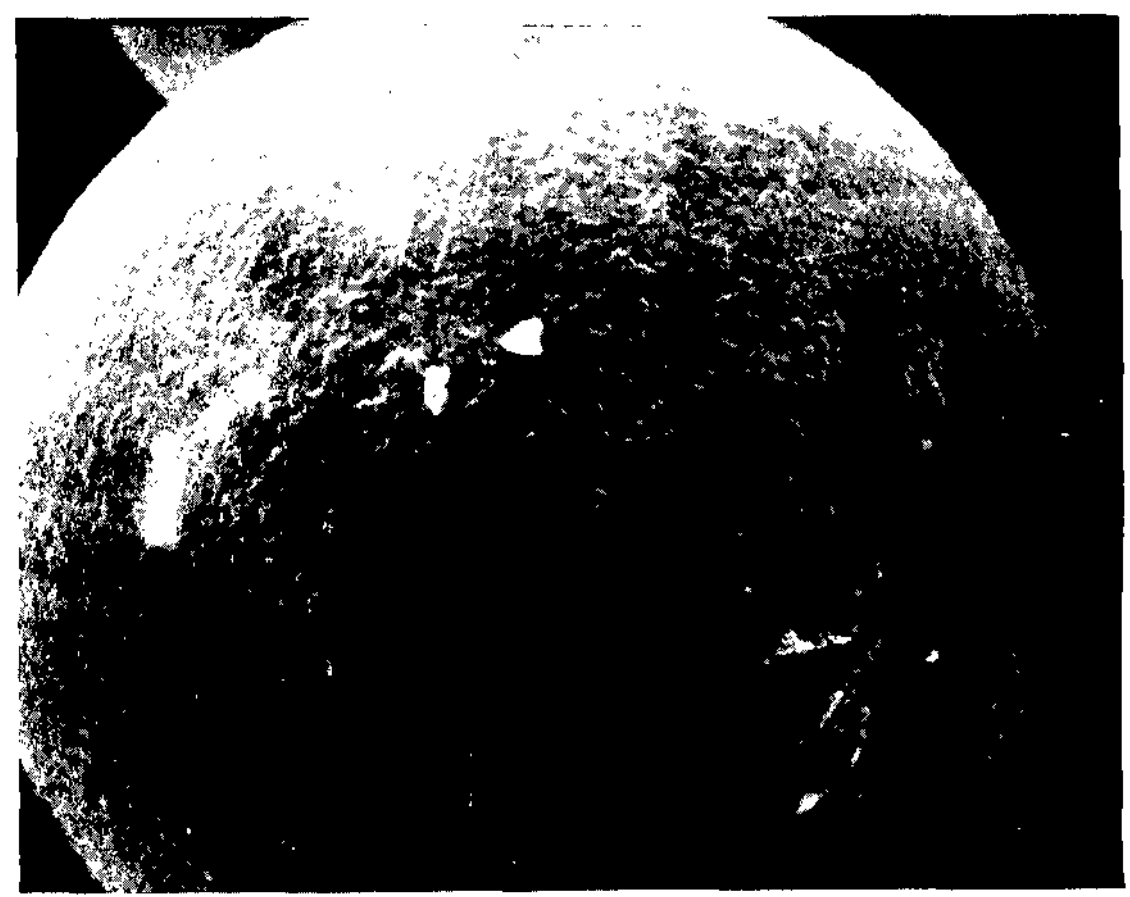

$4 \mathrm{Kw} \cdot \mathrm{Hr} / \mathrm{L}$ Irradiation (2000X)

FIGURE 15. Resin Bead Before and After ${ }^{60} \mathrm{Co}$ Irradiation 

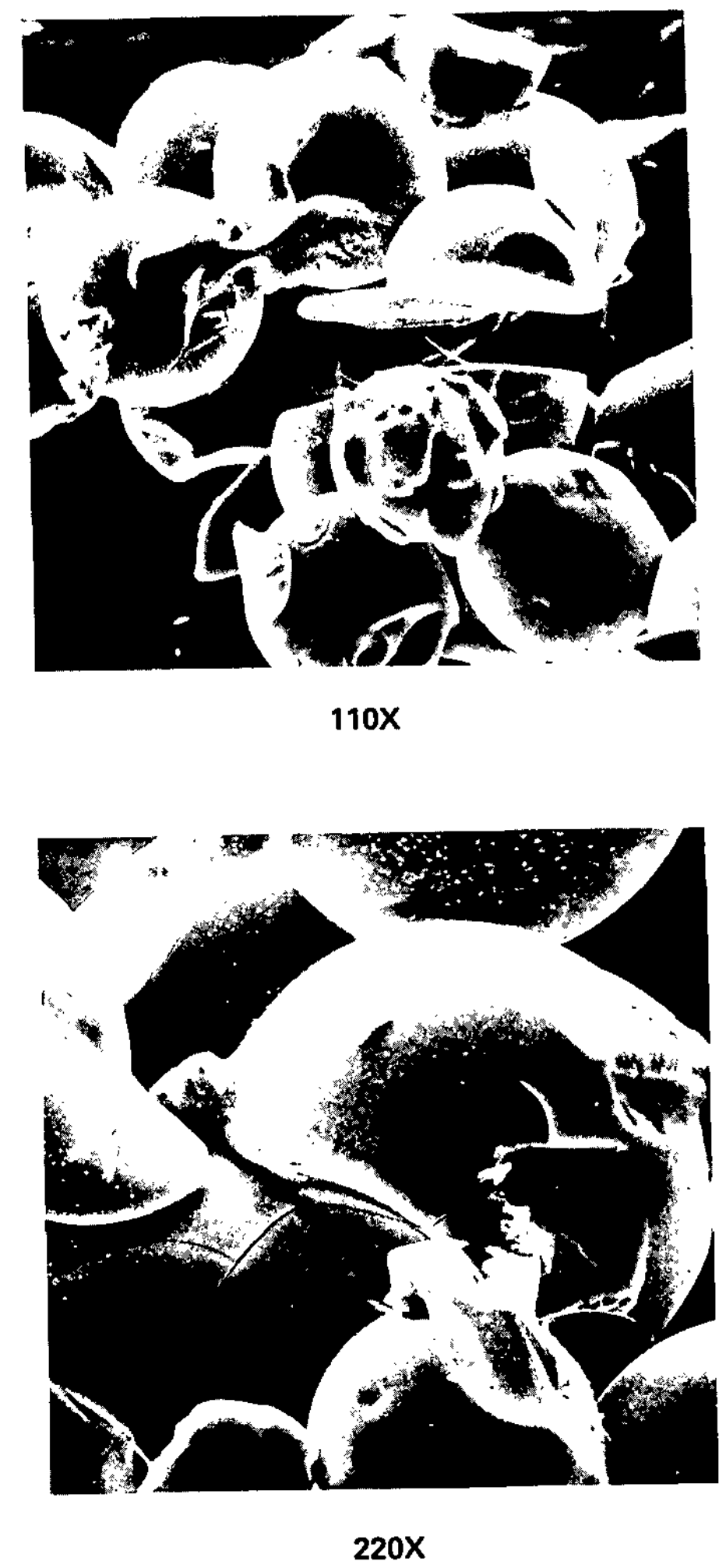

FIGURE 16. Resin Beads Irradiated by ${ }^{241} \mathrm{Am}$ to $2 \mathrm{kN}-\mathrm{hr} / \mathrm{L}$ 


\section{DTPA Tests}

In MPPF chemical separations, DTPA is used as an eluant in ion-exchange operations and also as a flushing agent at the end of the process. Concentrations of $0.05 \mathrm{M}$ DTPA will be used for eluting, and $0.3 \mathrm{M}$ for flushing. Since DTPA is a chelating agent, it will complex the iron catalyst and hinder resin dissolution. A cleaning cycle is necessary to remove DTPA residue after an $\mathrm{Am}-\mathrm{Cm}$ separation run. The developed cleaning cycle consists of four phases, in the following order: 2-bed volumes of $0.1 \mathrm{M} \mathrm{NH}_{4} \mathrm{OH}, 2-$ bed volumes of water, 2-bed volumes of $1 \mathrm{M} \mathrm{HNO}_{3}$, and 3-bed volumes of water. The nitric acid is used to recondition the resin to the acid form. Resin treated with both $0.05 \mathrm{M}$ and $0.3 \mathrm{M}$ DTPA, followed by the same cleaning procedure, was dissolved by hydrogen peroxide. The dissolution time for resin treated with $0.3 \mathrm{M}$ DTPA was increased significantly (Figure 17). Analyses indicated that approximately $1.41 \times 10^{-3}$ gram of DTPA remained per gram of resin.

\section{ChBMICAL ANALYSIS}

The IR spectral analysis of dissolved resin solution indicated that the aromatic sulfonic acids were intact, but the crosslinks were oxidized. This oxidation introduced a substantial number of carboxyl groups. The dissolved resin was identified as a linear polymer, not a monomer, in agreement with previous studies. 3

The dissolution condensate had an organic odor. It contained a small quantity of acetone and sulfonic acid compounds. A potassium tracer test proved that these organics were carried over by distillation. Table 1 ists the typical analyses of dissolution products for 33 and $9.5 \%$ resin slurries.

The dissolved resin solution still contained some quantities of organic matter (residue on evaporation). This indicates that the resin was not totally oxidized to $\mathrm{CO}_{2}$ during dissolution. Rather, the resin was only partially decomposed to become soluble as suggested earlier.

The acid concentration is substantially higher than the $0.1 \mathrm{M}$ $\mathrm{HNO}_{3}$ used in dissolution, because some of the resin is converted to sulfonic acid. 


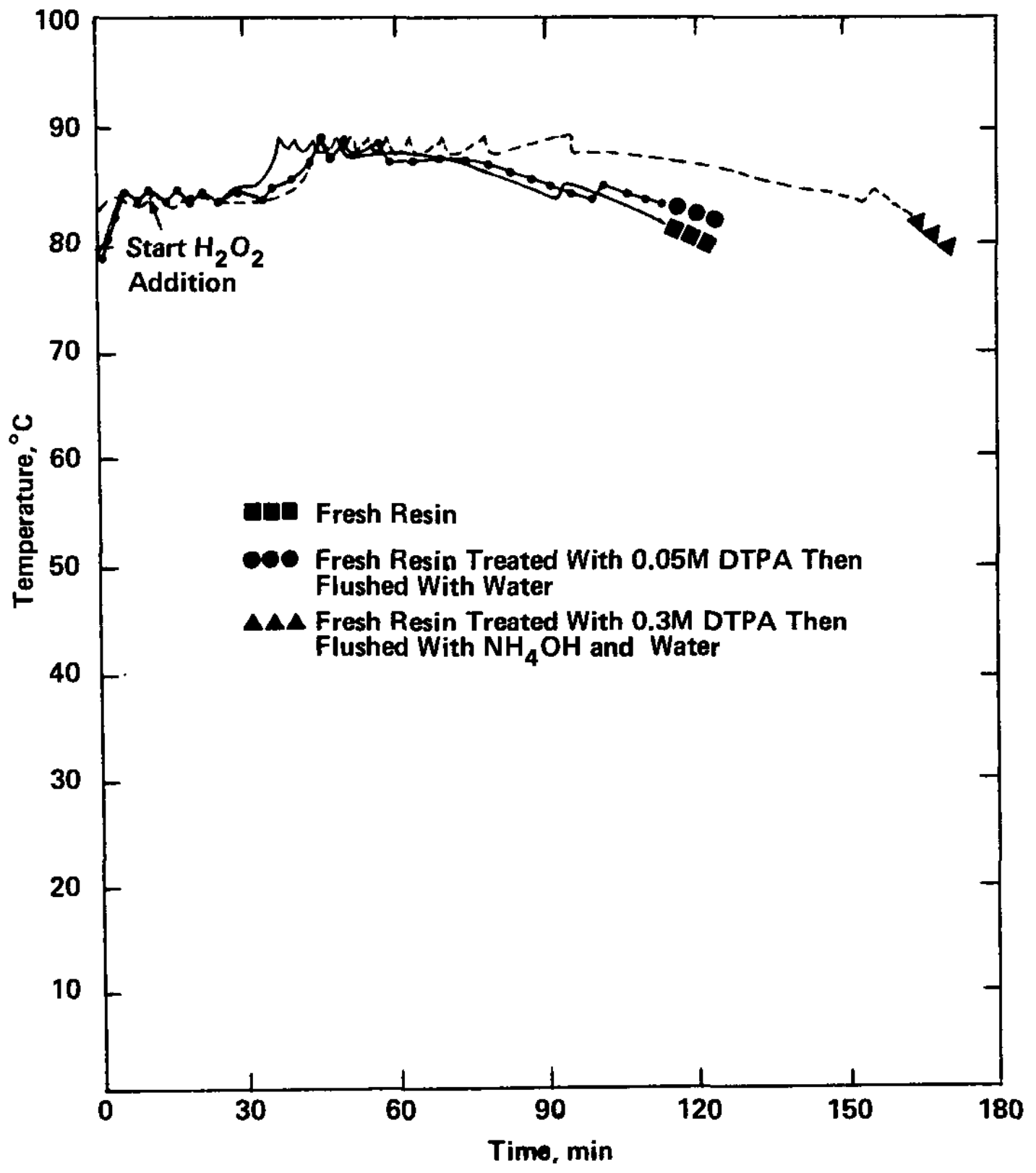

FIGURE 17. Effect of Resin With DTPA Residue on Dissolution 


\section{TABLE 1}

Typical Analytical Data for Dissolution Products

\begin{tabular}{|c|c|c|c|c|}
\hline \multirow[b]{2}{*}{ Analyis } & \multicolumn{2}{|c|}{ Resin Solutions } & \multicolumn{2}{|l|}{ Condensates } \\
\hline & $9.5 \%$ & $33 \%$ & $9.5 \%$ & $33 \%$ \\
\hline Sulfur & $0.48 \%$ & $1.72 \%$ & $6 \mathrm{ppm}$ & $2 \mathrm{ppm}$ \\
\hline Carbon & $1.2 \%$ & $5.6 \%$ & $0.159 \%$ & $0.187 \%$ \\
\hline Carbon/Sulfur Atomic Ratio & 6.7 & 8.7 & - & - \\
\hline Residue on Evaporation & $2.95 \%$ & $11.32 \%$ & $0.015 \%$ & $0.0096 \%$ \\
\hline Density & 1.0147 & 1.0502 & 0.9943 & 0.9970 \\
\hline $\mathrm{H}^{+}$ & 1.04 & 0.89 & 0.012 & 0.015 \\
\hline $\mathrm{NO}_{3}^{+}$ & $0.114 \mathrm{M}$ & $0.116 \mathrm{M}$ & $2.13 \times 10^{-4} \mathrm{M}$ & $1.24 \times 10^{-4} \mathrm{M}$ \\
\hline
\end{tabular}




\section{CORCLUSION}

Based on resin dissolution tests at the SRL Semiworks, it is concluded that a plant-scale resin dissolution can be carried out safely in the full-scale reprocessing plant.. The following parameters are recommended for resin dissolution:

$\mathrm{HNO}_{3}$ concentration: $0.1 \mathrm{M}$

Catalyst concentration: $0.001 \mathrm{M} \mathrm{Fe}^{3+}$

Volume of pure $\mathrm{H}_{2} \mathrm{O}_{2}$ /batch volume: 3 vol \%

Temperature setting: 85 to $90^{\circ} \mathrm{C}$

Air sparging rate: 1.0 to $1.5 \mathrm{scfm}$

Peroxide addition rate: 100 to $300 \mathrm{~mL} / \mathrm{min}$

Resin slurry concentration: $<40$ vol \% 


\section{REFERENCES}

1. N. E. Bibler and E. G. Orebaugh. "Iron-Catalyzed Dissolution of Polystyrene Sulfonate Cation-Exchange Resin in Hydrogen Peroxide." Ind. Eng. Chem., Prod. Res. Dev. 15, 136 (1976).

2. L. S. Goldring. "The Oxidative Degradation of Ion-Exchange Resin and Its Prevention." Proceedings of the International Conference on The Theory and Practice of Ion Exchange. Cambridge, England (1976).

3. R. Signer and A. J. Demagistri. "Preparation and Properties of Acid Polystyrene Sulfonates." Chem. Phys. 47, 704 (1950).

4. A. R. Kazanjian and D. R. Horrel1. Gamma Irradiation of Dowex 50W. REP-2140, Dow Chemical U.S.A., Rocky Flats Plant, Golden, Colorado (May 10, 1974).

5. A. R. Kazanjian and D. R. Horrell. Alpha Irradiation of Dowex 50W. REP-2298, Dow Chemical U.S.A., Rocky Flats Plant, Golden, Colorado (February 27, 1975). 